\title{
Licófitas e samambaias do Parque Estadual Monte Alegre (PEMA), Pará, Brasil
}

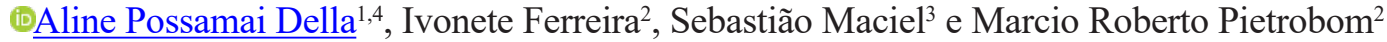 \\ Recebido: 7 agosto 2018; aceito: 23 julho 2019
}

Como citar: Della, A.P., Ferreira, I., Maciel, S. \& Pietrobom, M.R. 2019. Licófitas e samambaias do Parque Estadual Monte Alegre (PEMA), Pará, Brasil. Hoehnea 46: e732018. http://dx.doi.org/10.1590/2236-8906-73/2018.

\begin{abstract}
Lycophytes and ferns of the Parque Estadual Monte Alegre (PEMA), Pará State, Brazil). The Cerrado is an important phytogeographic Brazilian domain that covers a considerable percentage of the national territory. Although there are few studies highlighting the importance of ferns and lycophytes in the Cerrado, it is estimated that 241 to 248 species occur in this phytogeographic domain. Therefore, the objective of this study was to perform a survey of the Pteridophytes of a Cerrado area, located in the State of Pará and to present an identification key for the species. We used the walking methodology of sampling in areas with terra firme forest on slopes, in rocky outcrops, and at the entrance of caves. We obtained two lycophytes and 18 ferns species, belonging to nine families, being Pteridaceae, Anemiaceae, and Polypodiaceae the most representative. This result was similar to previous studies carried out in this domain. Two species with no herbarium records in the northern region were found: Anemia elegans (Gardner) C. Presl, and Cheilanthes eriophora (Fée) Mett. An identification key for the species using reproductive and vegetative characters was elaborated. Floristic studies including Pteridophytes are important because they contribute with the knowledge about the biology and distribution of this group of plants in the Cerrado, as well as in the Pará flora.
\end{abstract}

Keywords: biodiversity, cerrado, ferns, floristic, taxonomy

RESUMO - (Licófitas e samambaias do Parque Estadual Monte Alegre (PEMA), Pará, Brasil). O Cerrado é um importante domínio fitogeográfico brasileiro, uma vez que abrange porcentagem considerável do território nacional. Nesse domínio há estimativas de 241 a 284 espécies de samambaias e licófitas, apesar disso, há poucos trabalhos ressaltando-as nesse ambiente, assim o objetivo desse estudo foi realizar um levantamento das plantas vasculares sem sementes de uma área de Cerrado, localizada no Pará; bem como apresentar uma chave de identificação para as espécies. Para isso empregamos o método de caminhamento em áreas com vegetação de terra firme nas encostas, em afloramentos rochosos e nas entradas de cavernas. Obtivemos duas espécies de licófitas e 18 de samambaias, pertencentes a nove famílias, sendo Pteridaceae, Anemiaceae e Polypodiaceae as mais representativas, o que também foi verificado em estudos similares nesse domínio. Duas espécies sem registros em herbários da região norte foram encontradas: Anemia elegans (Gardner) C. Presl e Cheilanthes eriophora (Fée) Mett. Uma chave de identificação foi elaborada para as espécies, empregando caracteres reprodutivos e vegetativos. Estudos florísticos que incluem Pteridófitas são importantes porque contribuem para ampliar nosso conhecimento sobre a biologia e a distribuição desse grupo de plantas no Cerrado, bem como na flora paraense.

Palavras-chave: biodiversidade, cerrado, florística, pteridófitas, taxonômia

\section{Introdução}

As licófitas e samambaias compreendem duas linhagens evolutivas distintas de plantas vasculares sem sementes (Pryer et al. 2001), que apresentam atualmente 1338 e 10578 espécies, respectivamente (PPG I 2016). Esses grupos apresentam ampla distribuição geográfica, com muitas espécies

1. Universidade de São Paulo, Instituto de Biociências, Programa de Pós-Graduação em Botânica, Cidade Universitária, Rua do Matão, travessa 14, n 321, 05508-090 São Paulo, SP, Brasil

2. Universidade Federal do Pará, Instituto de Estudos Costeiros, Campus de Bragança, Alameda Leonardo Ribeiro s/n, Aldeia, 68600000 Bragança, PA, Brasil

3. Universidade Federal do Pará, Faculdade de Ciências Biológicas, Campus Universitário Marajó/Soure, 13ª rua s/n, Umirizal, 68870000 Soure, PA, Brasil

4. Autor para correspondência: alinepossamaidella@hotmail.com 
consideradas cosmopolitas, ocorrendo desde o nível do mar até os Páramos andinos, distribuindo-se pelas regiões tropicais e subtropicais até as regiões temperadas próximas aos círculos polares (Tryon \& Tryon 1982).

Nas Américas estima-se a ocorrência de 3250 espécies, sendo que dessas, 40\% (ca. 1326 espécies) podem ser encontradas no território brasileiro (Tryon \& Tryon 1982, Windisch 1990). No Brasil, que apresenta centros de endemismos (Tryon \& Tryon 1982), estão distribuídas em todos os domínios fitogeográficos, sendo, no entanto, mais representativos na Mata Atlântica (925 espécies) e na Amazônia (550 espécies) (Zuquim et al. 2012, Flora do Brasil 2020 em construção).

No Cerrado, que abrange cerca de $22 \%$ do território nacional (BRASIL 2018) e apresenta diferentes fisionomias (formações savânicas, campestres e florestais), há estimativas atuais de ocorrência de 241 a 284 espécies (Miguez et al. 2013, Souza 2014, Zambiase et al. 2016, Flora do Brasil 2020 em construção), dessas $76 \%$ ocorrem em formações florestais (como florestas de galerias) e em formações rupestres (Athayde-Filho \& Felizardo 2010, Miguez et al. 2013). Demonstrando que esse domínio tem uma flora rica em licófitas e samambaias, ao contrário do que se acreditava (Windisch 1996).

Apesar dessas altas estimativas de ocorrência de espécies, a ocupação desordenada, a fragmentação de habitats, a erosão de solo, a poluição de aquíferos, a alteração no regime de queimadas, e a invasão por espécies exóticas (Pinheiro \& Durigan 2009), estão consequentemente colocando em risco essa diversidade. Aliado a isso estão os escassos estudos, bem como as poucas ações concretas planejadas e realizadas visando a conservação do Cerrado (Pinheiro \& Durigan 2009).

Exclusivamente com as licófitas e samambaias, pode-se citar os seguintes estudos já realizados nesse domínio: Simabukuro et al. (1994) em São Paulo; Fernandes et al. (2007), Conceição et al. (2015) e Silva et al. (2017) no Maranhão; Athayde-Filho \& Agostinho (2005), Felizardo \& Athayde-Filho (2005), Athayde-Filho \& Felizardo (2010), Forsthofer \& Athayde-Filho (2012), e Miguez et al. (2013) no Mato Grosso; Lehn \& Assis (2013) no Mato Grosso do Sul; Rocha (2008) e Zambiase et al. (2016) em Goiás. Pode-se citar também alguns estudos com angiospermas, mas que também incluíram amostragem desses grupos, tais como: Roveratti (2008), Silva (2009), Forsthofer et al. (2013), e Souza
(2014). Para o Estado do Pará há registro de apenas um trabalho com licófitas e samambaias em áreas de Cerrado realizado por Pallos et al. (2016) para a Serra Itauajuri (município de Monte Alegre), constituída por um mosaico de vegetação, com áreas de cerrado no topo da serra.

Assim, o objetivo desse estudo foi realizar um levantamento das espécies de licófitas e samambaias de uma área de Cerrado, localizada no Estado do Pará, bem como apresentar uma chave de identificação para esses táxons com base em caracteres reprodutivos e vegetativos.

\section{Material e métodos}

Área de estudo - O Parque Estadual Monte Alegre (PEMA) é uma Unidade de Conservação de Proteção Integral, criada pela lei estadual 6.412 ( 9 de novembro de 2001), localizada no município de Monte Alegre, na mesorregião do Baixo Amazonas, no Estado do Pará (figura 1), entre as coordenadas de $00^{\circ} 22^{\prime} 52^{\prime \prime}$ de latitude norte e $02^{\circ} 25^{\prime} 34^{\prime \prime}$ de latitude sul, e de $53^{\circ} 41^{\prime} 10^{\prime \prime}$ de longitude leste e de 54 $54^{\prime}$ ' $13^{\prime \prime}$ de longitude oeste (BRASIL, 2009).

O PEMA abrange cerca de 5.800 hectares, cuja vegetação é, em sua maior parte, florística e estruturalmente composta de encraves de Cerrado, em solo arenoso bastante frouxo, localmente conhecidos como "Campos de Monte Alegre" (PEMA 2009). Nestes, pode-se observar uma vegetação mais fechada assemelhando-se a um Cerradão ao longo das encostas, e uma vegetação de Campos, em solo erodido, com predomínio de Poaceae e Cyperaceae, nas escarpas mais íngremes das serras (PEMA 2009). Em menor extensão, há remanescentes de Floresta Amazônica em vários estágios de regeneração, os mais avançados sendo formados por um estrado superior com árvores de 20-25m, e com algumas emergentes chegando a $30 \mathrm{~m}$. Nas áreas de transição da Floresta Amazônica com Cerrado são encontradas capoeiras com árvores de até $5 \mathrm{~m}$ de altura (PEMA 2009).

O clima dominante no município de Monte Alegre é o tipo AWi, clima tropical chuvoso de acordo com a classificação de Köppen, e a temperatura média mensal varia de 25.7 a $27.7^{\circ} \mathrm{C}$. A estação chuvosa é de fevereiro a maio com precipitações pluviométricas médias mensais superiores a $200 \mathrm{~mm}$, sendo abril, o mês de pico da estação chuvosa (317.2 mm); setembro a novembro são os meses menos chuvosos, com médias inferiores a $50 \mathrm{~mm}$ (Oliveira Jr. 1998). 


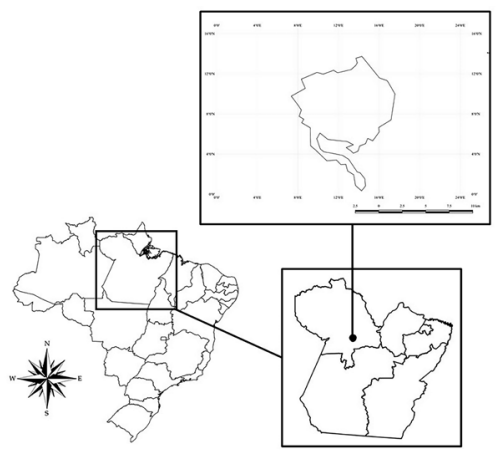

Figura 1. Localização do Parque Estadual Monte Alegre (PEMA), em Monte Alegre, Estado do Pará, Brasil.

Figure 1. Figure 1. Location of Parque Estadual Monte Alegre (PEMA), in Monte Alegre, Pará State, Brazil.

Coleta, identificação e herborização - A coleta do material botânico foi realizada em maio de 2010, por meio do método de "Caminhamento" (Filgueiras et al. 1994), em diferentes ambientes, com vegetação de terra firme nas encostas, nos afloramentos rochosos e nas entradas de cavernas localizadas em áreas Cerrado do PEMA. Os espécimes foram coletados e herborizados segundo a metodologia padrão para plantas vasculares, tal como descrito por Fidalgo \& Bononi (1989), e o material testemunho foi incorporado no acervo do Herbário HBRA da Universidade Federal do Pará (UFPA), Campus de Bragança.

A identificação do material foi realizada com o auxílio de revisões taxonômicas e floras regionais brasileiras, e de outros países que compõem o Neotrópico. A circunscrição aceita neste trabalho para as famílias e gêneros de licófitas e samambaias está de acordo com o PPG I (2016).

A distribuição geográfica das espécies, nos países do continente americano, bem como sua ocorrência em outros continentes, foi estimada com base em Moran \& Riba (1995), Smith (1995) e Mickel \& Smith (2004), e nas demais obras utilizadas na identificação das espécies. Foi adotado os padrões de distribuição propostos por Parris (2001), Moran \& Smith (2001), Silva et al. (2005) e Schwartsburd \& Labiak (2007), sendo que as espécies foram consideradas: Americana (quando presentes nos Estados Unidos até a Argentina), Sul-Americana (presentes apenas nos países da América do Sul), Pacífica (presentes na América, Ásia ou Oceania), e Brasil (restritas ao Brasil). Os hábitos de vida estão de acordo com a classificação proposta por Paciência (2008), os habitats de acordo com Lellinger (2002), e para os ambientes de ocorrência considerou-se as seguintes categorias: afloramento de água, bloco rochoso, borda de caverna, encosta de serra; fenda de rocha e paredão rochoso.

A chave de identificação, aqui apresentada, para as espécies foi elaborada através da observação de características morfológicas de plantas adultas verificadas no PEMA, sendo priorizados características facilmente observadas.

\section{Resultados e Discussão}

Foram verificadas na área de estudo um total de 20 espécies (duas de licófitas e 18 de samambaias), agrupadas em 12 gêneros e nove famílias (tabela 1). Somente um espécime não foi identificado ao nível de espécie, o qual foi tratado como Selaginella sp., isso em função da taxonomia desse gênero ser difícil, e pela ausência de revisões recentes para este grupo. As famílias com maior riqueza foram: Pteridaceae, Polypodiaceae e Anemiaceae, com cinco, três e três espécies, respectivamente.

Estudos similares realizados no Distrito Federal (DF) e nos Estados do Maranhão (MA), Mato Grosso (MT), Mato Grosso do Sul (MS) e São Paulo (SP), verificaram de 13 a 36 espécies de licófitas e samambaias em áreas de Cerrado (Simabukuro et al. 1994, Fernandes et al. 2007, Forsthofer \& Athayde Filho 2012, Lehn \& Assis 2013, Souza 2014, Silva et al. 2017), e as famílias mais ricas foram: Pteridaceae, Thelypteridaceae, Blechnaceae e Polypodiaceae. Uma maior quantidade de espécies foi obtida em trabalhos que incluíram amostragem em áreas de mata ciliares, tais como Simabukuro et al. (1994), Lehn \& Assis (2013) e Souza (2014). A alta riqueza de samambaias em ambientes de borda de rio pode ser explicada pelas características ambientais favoráveis ao estabelecimento e a reprodução dessas plantas presente nessas localidades, tais como: maior umidade e sombreamento (Zambiase et al. 2016). O que destaca a importância da preservação e conservação dessas áreas à manutenção de muitas espécies, que são inclusive endêmicas desse tipo de vegetação.

Em estudo realizado em área de transição de Cerrado e Floresta Amazônica no MT por Forsthofer et al. (2013), verificaram sete espécies de samambaias, pertencentes a Pteridaceae com cinco espécies, e Polypodiaceae com duas. Os resultados obtidos nesses trabalhos foram similares aos deste estudo.

Dentre as espécies presentes na área, destacam-se Telmatoblechnum serrulatum (Rich.) Perrie, D.J. 


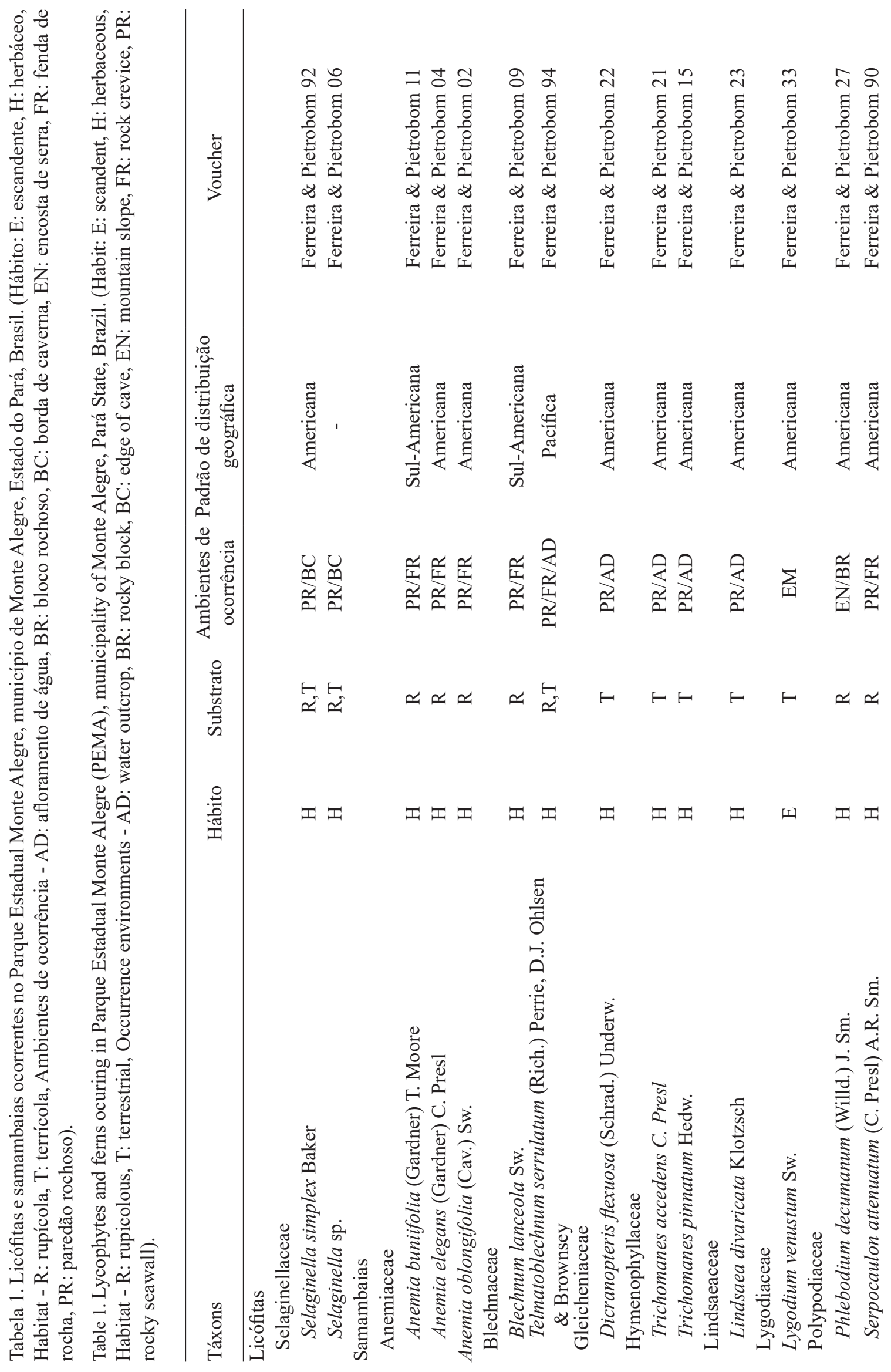




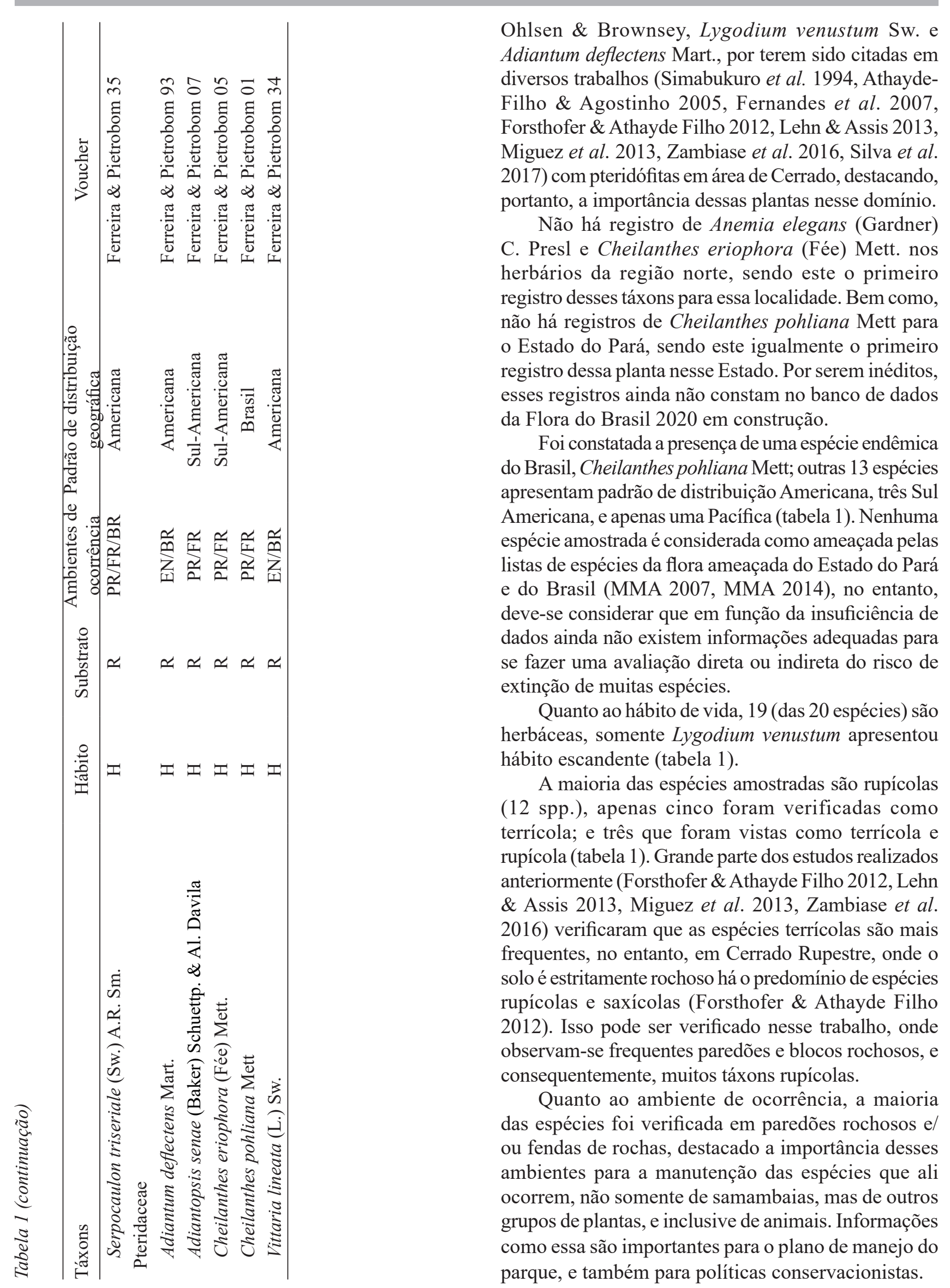


Chave de identificação para as espécies de licófitas e samambaias do Parque Estadual Monte Alegre, Pará, Brasil

1. Folhas com apenas uma nervura não ramificada; esporângio único localizado na axila da superfície adaxial dos microfilos; folhas do tipo microfilos

2. Micrófilo dorsal estreitamente lanceolado, base equilateral; margens dos micrófilos obscuramente hialinas; megásporo verde-amarelado Selaginella simplex

2. Micrófilo dorsal ovalado, base inequilateral; margens dos micrófilos não hialinas; megásporo esbranquiçado..... Selaginella sp.

1. Folhas com venação ramificada, aberta ou areolada; esporângios numerosos sobre a superfície abaxial ou na margem da lâmina; folhas do tipo megáfilos

3. Esporângios sésseis ou subsésseis; anel horizontal, oblíquo ou apical não interrompido pelo pedicelo

4. Esporângios com anel apical, agrupados em estruturas especializadas (soróforos) na margem da lâmina

5. Frondes trepadeiras, de crescimento indeterminado; cada esporângio recoberto pela margem da lâmina modificada em pseudo-indúsio Lygodium venustum

5. Frondes não trepadeiras, de crescimento determinado; esporângios em segmentos marginais nus (não recoberto por pseudo-indúsio), ou em panículas em porções especializadas de segmentos, ou em pinas modificadas e reduzidas

6. Frondes dimorfas; lâmina estéril finamente dividida em segmentos $<0,5 \mathrm{~mm}$ larg.; pina estéril mais ou menos dicotomicamente ramificada . Anemia buniifolia

6. Frondes monomorfas; lâmina estéril grossamente dividida em segmentos $>1$ mm larg.; pina estéril inteira a pinatífida, não mais ou menos dicotomicamente ramificada 7. Frondes formando uma roseta achatada, pinatífidas, sésseis, com lobos basais férteis Anemia elegans

7. Frondes eretas e espalhadas, pinadas, com pinas basais férteis, eretas, pecioladas Anemia oblongifolia

4. Esporângios com anel horizontal a oblíquo, agrupados entre a costa e a margem da lâmina, submarginais ou marginais, neste caso não formando soróforos

8. Soros entre a costa e a margem da lâmina; indúsio ausente; esporos sem clorofila; lâmina cartácea, com várias células em espessura, opacas; frondes pseudodicotomicamente divididas . Dicranopteris flexuosa

8. Soros marginais; indúsio tubular, cônico ou bivalvado; esporos com clorofila; lâmina membranácea, geralmente com 1-2 células em espessura, translúcida; frondes pinatífidas a 1-pinado-pinatífidas

9. Indúsio imerso no tecido; lâmina pilosa; falsas vênulas ausentes Trichomanes accedens

9. Indúsio livre no tecido, curto pedunculado; lâmina glabra; falsas vênulas presentes

Trichomanes pinnatum

3. Esporângios pedicelados; anel vertical interrompido pelo pedicelo

10. Pecíolo da fronde com 2 feixes vasculares na base; soros marginais, protegidos por pseudo-indúsio

11. Lâmina 1-pinada; pínula com 4.0-10,8 mm compr., 3.0-20.0 mm larg.; margem da pina estéril denticulada; cor do peciólulo terminando abruptamente na base da pina ..... Adiantum deflectens

11. Lâmina 2-pinada; pínula com 2.0-3.0 mm compr., 1.0-1,5 mm larg.; margem da pínula estéril inteira; cor do peciólulo passando a base da pínula e tornando-se gradualmente da mesma cor do tecido laminar Adiantopsis senae

10. Pecíolo da fronde com 1, 3 ou mais feixes vasculares na base; soros entre a costa e a margem da lâmina, submarginais ou marginais, neste caso pseudo-indúsio ausente

12. Esporângios agrupados em cenosoros, paralelos e adjacentes à costa

13. Folhas geralmente inteiras, podendo ocorrer na mesma planta folhas pinatífidas, com 1-3 lobos basais; pinas não articuladas à raque; caule ereto, curto Blechnum heringeri 13. Folhas 1-pinadas; pinas articuladas à raque; caule longo-reptante Telmatoblechnum serrulatum 
12. Esporângios agrupados em soros arredondados, alongados a lineares, se alongados ou lineares, estes paralelos e próximos da margem da lâmina

14. Caule reptante com duas fileiras de frondes na superfície dorsal do caule; pecíolo articulado ao caule; soros arredondados e sem indúsio; lâmina geralmente pinatissecta a 1-pinada; pínulas não dimidiadas

15. Aréolas com 2 vênulas excurrentes unidas em suas extremidades que abastecem os soros; caule com escamas concolores, não clatradas, avermelhadas a alaranjadas

Phlebodium decumanum

15. Aréolas com 1 vênula excurrente que abastece os soros; caule com escamas bicolores, clatradas, glaucas

16. Soros comumente em 1 fileira entre a costa e a margem da lâmina; escamas do caule clatradas, amplamente ovaladas Serpocaulon attenuatum

16. Soros em 2(-3) fileiras irregulares entre a costa e a margem da lâmina; escamas do caule subclatradas, estreitamente ovaladas Serpocaulon triseriale

14. Caule ereto, geralmente com frondes dispostas em espiral, ou caule reptante, neste caso com pecíolo não articulado, se articulado então soros do tipo acrosticóide ou soros indusiados; lâmina inteira, 1-pinado-pinatífida, 2-pinatífida ou pedada e pentagonal, se lâmina 1-2-pinada, então com pínulas dimidiadas

17. Lâmina inteira, linear; esporângios em soros lineares, submarginais, sem indúsio

Vittaria lineata

17. Lâmina 1-pinado-pinatífida ou pedada e pentagonal, se 1-2-pinada, então com pínulas dimidiadas; esporângios em soros circulares a lineares, marginais ou submarginais, com indúsio ou pseudo-indúsio

18. Esporângios em soros submarginais, formados na confluência de duas ou mais nervuras unidas por uma comissura vascular, coberto por indúsio verdadeiro, abrindo-se em direção à margem da lâmina; lâmina 1-2-pinada, com pínulas dimidiadas Lindsaea divaricata

18. Esporângios em soros marginais na extremidade da nervura, frequentemente coberto pela margem da lâmina recurvada; lâmina 1-pinado-pinatífida a 2-pinada, sem pínulas dimidiadas

19. Lâmina pentagonal, pedado-pinatífida, tomentosa; pina basal inequilateral; pseudo-indúsio geralmente ausente; escamas do caule com margem ciliada. Cheilanthes eriophora

19. Lâmina lanceolada, pubescente; pina basal equilateral; pseudo-indúsio presente, piloso; escamas do caule com margem denticulada ...... Cheilanthes pohliana

\section{Conclusão}

Há uma diversidade considerável de licófitas e samambaias na área estudada e algumas das espécies verificadas já vem sendo destacadas em estudos com esses grupos em áreas de Cerrado, evidenciando a importância desses táxons para a flora desse domínio. Ressalta-se também a existência de espécies que ainda não tinham registro para a região norte do país, demonstrando que trabalhos como esse são extremamente necessários para o conhecimento da nossa flora, e principalmente, da flora do Estado do Pará, que ainda é pouco explorada. E por último, evidencia-se a importância do conhecimento da flora do PEMA para a elaboração ou complementação do plano de manejo do parque.

\section{Agradecimentos}

Os autores agradecem ao Parque Estadual Monte Alegre (PEMA) pelo apoio logístico nas coletas de campo; à Universidade Federal do Pará pela infraestrutura fornecida; ao guia de campo Roberto de Deus; à família Ferreira pelo apoio logístico nas saídas a campo e pela estadia oferecida; ao editor associado e os revisores anônimos pelas correções e sugestões sobre esse artigo.

\section{Literatura citada}

Athayde-Filho, F.P. \& Agostinho, A.A. 2005. Pteridoflora de duas veredas no município de Campinápolis, Mato Grosso, Brasil. Pesquisas, Botânica 56: 145-160. 
Athayde-Filho, F.P. \& Felizardo, M.P.P. 2010. Análise florística e ecológica das samambaias e licófitas da principal nascente do rio Pindaíba, Mato Grosso. Pesquisas, Botânica 61: 229-244.

Conceição, G.M., Zárate, E.L.P., Ruggieri, A.C., Silva, E.O. \& Silva, M.F. 2015. Pteridoflora e seus aspectos ecológicos no município de Timon, Maranhão, Brasil. Brazilian Geographical Journal: Geosciences and Humanities research médium 6: 74-81.

Felizardo, M.P.P. \& Athayde-Filho, F.P. 2005. Pteridoflora de um cerrado stricto sensu no Parque Municipal Mario Viana em Nova Xavantina, MT. Resumos de $56^{\circ}$ Congresso Nacional de Botânica.

Fernandes, R.S., Conceição, G.M., Brito, E.S. \& Paula-Zárate, E.L. 2007. Diversidade florística de pteridófitas da Área de Preservação Ambiental do Inhamum, Caxias, Maranhão, Brasil. Revista Brasileira de Biociências 5: 411-413.

Fidalgo, O. \& Bononi, V.L.R. (coords.). 1989. Técnicas de coleta, preservação e herborização de material botânico. Manual 4. Instituto de Botânica, São Paulo.

Filgueiras, T.S., Brochado, A.L., Nogueira, P.E. \& Guala, G.F. 1994. Caminhamento - um método expeditivo para levantamentos florísticos qualitativos. Cadernos de Geociências 12: 39-43.

Forsthofer, M. \& Athayde-Filho, F.P. 2012. Florística e aspectos ecológicos de samambaias e licófitas ao longo do córrego cachoeirinha, Nova Xavantina-MT. Pesquisas, Botânica 63:149-164.

Forsthofer, M., Marimon, B.S., Abreu, M.F., OliveiraSantos, C., Morandi, P.S. \& Marimon-Junior, B.H. 2013. Monodinâmica arbórea e diversidade de samambaias em florestas de transição Cerrado-Floresta Amazônica, Brasil. Rodriguésia 64: 349-356.

Lehn, C.R. \& Assis, E.L.M. 2013. Riqueza de samambaias e licófitas de uma mata de galeria na região central de Mato Grosso do Sul, Brasil. Biotemas 26: 7-15.

Lellinger, D.B. 2002. A modern multilingual glossary for taxonomic pteridology. 3 ed. The American fern society.

Mickel, J. T., Smith, A. R. \& Valdespino, I. A. 2004. The Pteridophytes of Mexico. Memoirs of the New York Botanical Garden 88: 550-602.

Miguez, F.A., Kreutz, C. \& Athayde-Filho, F.P. 2013. Samambaias e licófitas em quatro matas de galeria do município de Nova Xavantina, Mato Grosso, Brasil. Pesquisas, Botânica 64: 243-458.

MMA (Ministério do Meio Ambiente). 2007. Resolução COEMA No 54, de 24/10/2007. Disponível em https://sogi8.sogi.com.br/Arquivo/Modulo113. MRID109/Registro61138/documento\%201\%20 -\%20resolu\%C3\%A7\%C3\%A3o\%20coema\%20 n\%C2\%BA\%2054.pdf (acesso em 20-X-2018).
MMA (Ministério do Meio Ambiente). 2014. Portaria № 443, de 17 de dezembro de 2014. Disponível em http://cncflora.jbrj.gov.br/portal/static/pdf/portaria mma_443_2014.pdf (acesso em 20-X-2018).

MMA (Ministério do Meio Ambiente). 2009. Ministério do Meio Ambiente. Plano de Manejo do Parque Estadual Monte Alegre, Belém. Disponível em https://ideflorbio. pa.gov.br/wp-content/uploads/2014/10/Plano-deManejo-Pema.pdf (acesso em 20-10-2018).

MMA (Ministério do Meio Ambiente). 2018. Ministério do Meio Ambiente (Portal Eletrônico). O Bioma cerrado. Disponível em http://www.mma.gov.br/ biomas/cerrado (acesso em 06-IX-2018).

Moran, R.C. \& Riba, R. 1995. Polypodiaceae Vol. I. In: G. Davidse, M.S. Sousas, \& A.O. Chater (eds.). Flora Mesoamericana. Universidad Nacional Autónoma de México, México.

Moran, R.C. \& Smith, A.R. 2001. Phytogeographic relationships between neotropical and AfricanMadagascar pteridophytes. Brittonia 53: 304-351.

Oliveira Jr. 1998. Clima. Disponível em www.montealegre. rec.br/ aspectos /clima.html. (acesso em 05-IV-2010).

Paciência, M.L.B. 2008. Diversidade de pteridófitas em gradientes de altitude na Mata Atlântica do Estado do Paraná. Tese de Doutorado. Universidade de São Paulo, SP.

Pallos, J., Góes-Neto, L.A.A., Costa, J.M., Souza, F.S. \& Pietrobom, M.R. 2016. Licófitas e samambaias da Serra do Itauajuri, município de Monte Alegre, Pará, Brasil. Rodriguésia 67: 997-1009.

Parris, B.S. 2001. Circum-Antarctic continental distribution patterns in pteridophyte species. Brittonia 53:270-283.

PEMA. 2009. Plano de Manejo do Parque Estadual Monte Alegre. MMA/Secretaria de Extrativismo e Desenvolvimento Rural Sustentável, PROECOTUR, SEMA/PA.

Pinheiro, E.S. \& Durigan, G. 2009. Dinâmica espaçotemporal (1962-2006) das fitofisionomias em unidade de Conservação do Cerrado no sudeste do Brasil. Revista Brasileira de Botânica 32: 441-454.

PPG I. 2016. A community-derived classification for extant lycophytes and ferns. Journal of Systematics and Evolution 54: 563-603.

Pryer, K.M., Schneider, H., Smith, A., Cranfill, R., Wolf, P.G., Hunt, J.S. \& Sipes, S.D. 2001. Horsetails and ferns are a monofiletic group and the closest living relatives to seed plants. Nature 409: 618-622

Rocha, M.A.L. 2008. Inventário de espécies de pteridófitas de uma mata de galeria em Alto Paraíso, Goiás, Brasil e morfogênese dos gametófitos de Pecluma ptilodon (Kunze) Price e Campyloneurum phyllitidis (L.) C. Presl (Polypodiaceae). Dissertação de Mestrado, Universidade de Brasília. 
Samambaias e Licófitas in Flora do Brasil 2020 em construção. Jardim Botânico do Rio de Janeiro. Disponível em http://floradobrasil.jbrj.gov.br/reflora/ floradobrasil/F B128483 (acesso em 20-VII-2018).

Schwartsburd, P.B. \& Labiak, P.H. 2007. Pteridófitas do Parque Estadual de Vila Velha, Ponta Grossa, Paraná, Brasil. Hoehnea 34: 159-209.

Silva, J.M.C., Rylands, A.B. \& Fonseca, G.A.B. 2005. O destino das áreas de endemismo da Amazônia. Megadiversidade 1: 124-131.

Silva, J.S. 2009. Diversidade alfa, florística e fitossociologia na ARIE do Cerradão, na APA Gama e Cabeça de Veado, DF. Dissertação de Mestrado, Universidade de Brasília.

Silva, G.S., Silva, D.L.S., Oliveira, R.R., Silva, M.L.A. \& Conceição, G.M. 2017. Licófitas e samambaias no cerrado do leste do Maranhão, Brasil. Acta Brasiliensis 1: 13-16.

Simabukuro, E.A., Esteves, L.M. \& Felippe, G.M. 1994. Lista de pteridófitas da mata ciliar da Reserva Biológica de Moji Guaçu, SP. Insula 23: 91-98.

Smith, A.R. 1995. Pteridophytes. In: P.E. Berry, B.K. Holst \& K. Yatskievych (eds.). Flora of the Venezuelan Guyana. Pteridophytes, Spermatophytes, AcanthaceaeAraceae. v. 2. Missouri Botanical Garden \& Timber Press, Portland Oregon.
Souza, A.C.M. 2014. Comunidades de monocotiledôneas herbáceas e pteridófitas terrestres e suas relações com o ambiente em mata de galeria no Parque Nacional de Brasília. Dissertação de Mestrado, Universidade de Brasília.

Tryon, R. M. \& Tryon, A. F. 1982. Ferns and Allied Plants with Especial Reference to Tropical America. EspringVerlag, New York.

Windisch, P.G. 1996. Towards assaying biodiversity in Brazilian pteridophytes. In: C.E.M. BICUDO \& N.A. MENEZES. Biodiversity in Brazil: a first approach. CNPq, São Paulo, pp. 109-117.

Windisch, P.G. 1990. Pteridófitas da Região Norte Ocidental do Estado de São Paulo: Guia para estudo e excursões. UNESP, São José do Rio Preto.

Zambiase, R.M., Resende, I.L.M., Kreutz, C. \& Athayde-Filho, F.P. 2016. Análise ecoflorística de samambaias e licófitas em mata de galeria inundável e vereda, Quirinópolis, Goiás, Brasil. Pesquisas, Botânica 69: 169-181.

Zuquim, G., Tuomisto, H., Costa, F.R.C., Prado, J., Magnusson, W.E., Pimentel, T., Braga-Neto, R. \& Figueiredo, F.O.G. 2012. Broad scale distribution of ferns and lycophytes along environmental gradients in Central and Northern Amazonia, Brazil. Biotropica 44: $752-762$. 